\title{
Mustard Procedure for Simple Transposition of the Great Arteries
}

\author{
Eiji Ishizawa, Masamichi Tadokoro, Shigekazu Satoh, \\ Yasuyuki Suzuki, Kiyoshi Haneda, Yuzuru Kagawa \\ and Togo Horiuchi
}

The Department of Thoracic and Cardiovascular Surgery, Tohoku University School of Medicine, Sendai 980

\begin{abstract}
Ishizawa, E., Tadokoro, M., Satoh, S., Suzuki, Y., Haneda, K., Kagawa, Y. and Horiuchi, T. Mustard Procedure for Simple Transposition of the Great Arteries. Tohoku J. exp. Med., 1985, 145 (1), 91-96_— From May 1980 through April 1982, 9 patients underwent the Mustard operation for simple transposition of the great arteries (simple TGA) at the Tohoku University Hospital, Sendai. There was no early postoperative death, although one patient was lost with pulmonary venous obstruction in the late postoperative period. No pulmonary venous obstruction occurred since the introduction of expanded polytetrafluoroethylene (EPTFE) intraatrial baffle. Normal sinus rhythm has been preserved in all patients since direct, high superior vena cava cannulation was adopted. Postoperative hemodynamic study at an average 12 months after surgery revealed normal right ventricular function at rest. Work-function curve which is related to the right ventricular end-diastolic pressure and minute work index revealed good response of the right ventricle in two of three patients after methoxamine infusion test. All late survivors are acyanotic and clinically well. The Mustard procedure has dramatically improved the survival rate and quality of life for those with simple TGA. Presently, we continue to utilize the Mustard procedure for simple TGA until the superiority of other operations are demonstrated. - simple TGA; Mustard procedure; EPTFE intraatrial baffle; RV workfunction curve
\end{abstract}

The survival rate of patients with simple transposition of the great arteries (simple TGA) improved dramatically after balloon atrioseptostomy and the intraarterial baffle operation which was first introduced by Mustard (1963).

With accumulation of experiences, various problems associated with the Mustard procedure, i.e., arrhythmias, venous obstruction and late death, have been reported by many surgeons. However, appropriate technical modification during surgery, such as insertion of the cannula in the superior vena cava, selection of suture line, and preservation of the anterior portion of the atrial septum has contributed to decrease the frequency of arrhythmias to a great extent. The complications of the baffle problems have also become less reported by surgeons who are using different modified techniques.

Since 1966 at the Tohoku University Hospital in Sendai, we have striven to

Received for publication, May 28, 1984. 
improve the early and late results of the Mustard procedure. (Horiuchi et al. 1971 ; Ishizawa et al. 1979) The purpose of this report is to present our recent experiences with the Mustard procedure for simple TGA using "bypass hypothermia" at our institute.

\section{Method}

From May 1980 through April 1982, 9 patients underwent the Mustard procedure. The age of patients was from 40 day to 4 years, 9 months on an average (Fig. 1).

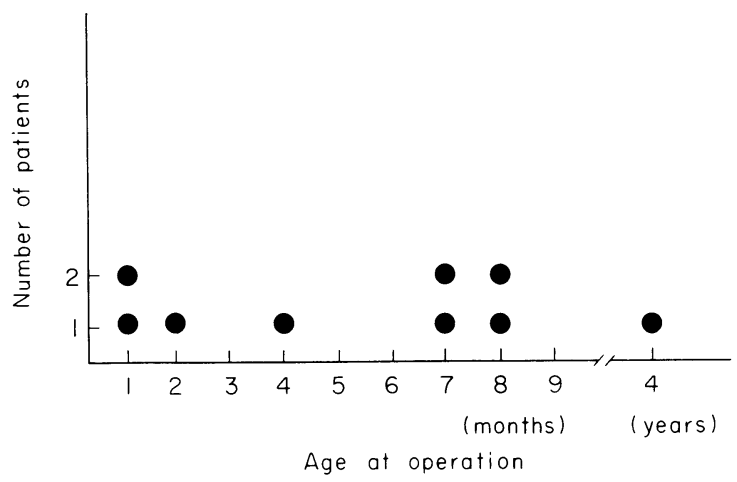

Fig. 1. Frequency distribution for patient age.

Their body weights were between 3 and $12 \mathrm{~kg}$. The sex distribution was 7 male and 2 female. All patients underwent cardiac catheterization and balloon atrial septostomy in the first week of life. A surgical atrioseptectomy was performed in two patients. The patients were treated with prostaglandin infusion to correct blood acidosis and improve its oxygen saturation for several weeks in the neonatal period before surgical intervention.

Moderate surface cooling was carried out in the ice water bath and the body temperature was lowered to about $24^{\circ} \mathrm{C}$. All operations were performed during a single period of circulatory arrest following exanguination at body temperature $16-18^{\circ} \mathrm{C}$.

An arterial perfusion cannula was placed in the ascending aorta and another one in the inferior vena cava through the right appendage. The superior vena cava was cannulated directly well above the S-A node just before the circulatory arrest. Using cardiopulmonary bypass, the body temperature was lowered to $16-18^{\circ} \mathrm{C}$ over a period of approximately 20 min. Then, the aorta was cross-clamped and a sufficient amount of cardioplegic solution to stop all electro-mechanical activity of the heart was injected into the aortic root. The heart was arrested and the circulation was completely stopped. The patient was exanguinated into the heart lung machine by gravity. The inferior vena cava cannula was removed from the right atrium. An incision was made just caudad to the right appendage as far as to the inferior vena cava. The intraatrial septum was removed widely, preserving the anterior portion of the atrial septum.

A trouser shaped intraatrial baffle made of expanded polytetrafluoroethylene (PTFE) sheet or graft was used in all but 2 patients. The coronary sinus was not incised but let to drain into the functional left atrium. If an intracardiac repair required more time than anticipated, cardiopulmonary bypass could be restarted. Cardiopulmonary bypass was discontinued when normal body temperature was achieved. Circulatory arrest time ranged from 40 to 55 min. 


\section{RESUlts}

There were no hospital death (Table 1). All patients recovered promptly from anesthesia. No evidence of abnormal neurological function was observed in any cases. Immediate postoperative ECG revealed normal sinus rhythm in all patients. There was one late death in this series. This 47 day old male infant had an uncomplicated postoperative course and was discharged from the hospital. He was readmitted 4 months after discharge with signs of pulmonary venous obstruction. Corrective surgery was undertaken. After surgical relief of this obstruction, the infant was weaned off from the bypass, but died in the early postoperative period in a low output state.

All late survivors are acyanotic and clinically well. Normal sinus rhythm has been confirmed at the latest check up at a mean of 21 months after operation.

As to the material for corrective atrial repair, a pericardial baffle was used in one case of pulmonary venous obstruction. Such complication did not occur in the other 8 patients who had EPTFE intraatrial baffle.

Six of the 8 late survivors underwent elective postoperative cardiac catherization. They were studied at an average interval of one year following the Mustard procedure.

In all patients the SVC and IVC were widely patent. This finding was evaluated by cineangiography and pressure withdrawal tracings. The mean pressure difference between the systemic venous atrium and both superior and inferior venae cavae was less than $3 \mathrm{mmHg}$. Resting withdrawal pressures from the main pulmonary artery to the left ventricle were obtained in 5 patients. These patients did not have significant left ventricular outflow obstruction, having a minor systolic pressure difference $(5-13 \mathrm{mmHg})$. The pulmonary arterial pressure and pulmonary vascular resistance were normal in all patients.

The right ventricular end-diastolic pressure was less than $10 \mathrm{mmHg}$. Cardiac index at the time of study was between $3.6-5.21 / \mathrm{min} / \mathrm{m}^{2}$.

Biplane cineangiography of the right ventricle was studied at a speed of 64 frames/sec in five patients. Right ventricular volumes were determined by Simpson's rule (Graham et al. 1973). Ejection fraction (EF) was calculated from an equation $\mathrm{EDV}+\mathrm{ESC} / \mathrm{EDV}$.

The right ventricular end-diastolic volume (RVEDV) was higher than normal in 4 patients but one. The total RVEDV averaged $178 \%$ of the normal value (Fig. 2). Right ventricular ejection fraction was normal in 4 patients and slightly

TABLE 1. Early and late mortality after Mustard procedure

\begin{tabular}{cccc}
\hline & \multirow{2}{*}{$\begin{array}{c}\text { Number of } \\
\text { patients }\end{array}$} & \multicolumn{2}{c}{ Mortality } \\
\cline { 3 - 4 } & 9 & Early & Late \\
\hline Simple TGA & 9 & 0 & 1 \\
\hline
\end{tabular}



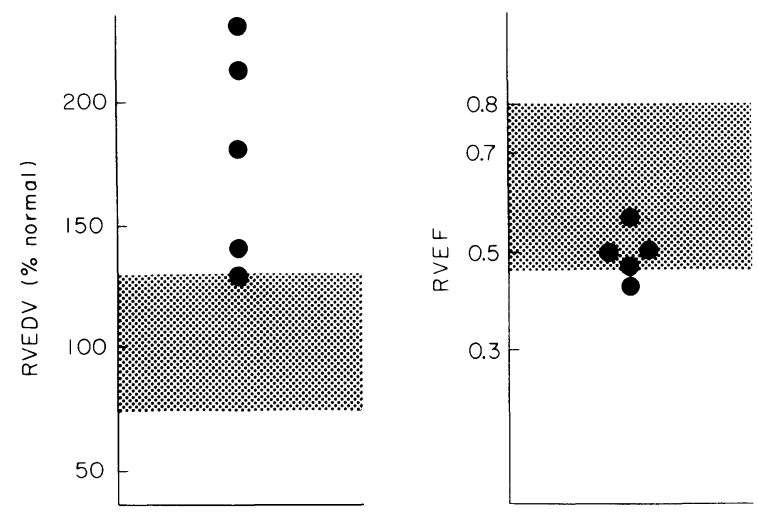

Fig. 2. Right ventricular end-diastolic volume (RVEDV) and right ventricular ejection fraction $(\mathrm{RVEF})$ at an average of one year after surgery. The RVEDV was higher than the normal in 4 patients but was normal in one patient. RVEDV averaged $178 \%$ for the total. RVEF was normal in 4 patients and was slightly depressed in one patient. Shaded area represents normal limits.

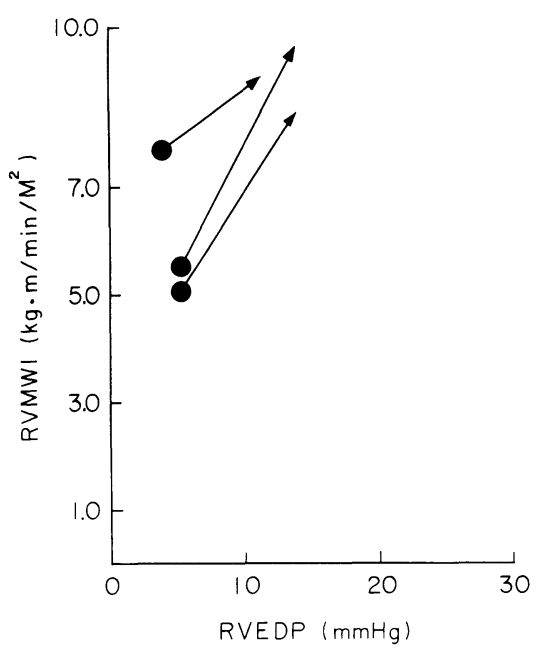

Fig. 3. Work-function curve which are related to the right ventricular end-diastolic pressure and minute work index in three patients at the late postoperative period. Two of three patients responded well to acute increase of afterload stress with methoxamine infusion test. The slopes were greater than 0.65 . Right ventricular minute work index (RVMWI) is calculated as : $\mathrm{RVMWI}=\mathrm{CI} \times(\mathrm{MSP}-\mathrm{EDP}) \times 0.0136$. Where $\mathrm{CI}=$ cardiac index, $\mathrm{MSP}=$ mean systolic pressure, EDP = end-diastolic pressure.

decreased in one patient.

The work-function curve which is related to the right ventricular enddiastolic pressure and minute work index were used for assessing the ventricular performance in 3 patients. All patients underwent the repair when they were younger than 5 months of age. All of them showed normal ventricular hemodynamics at rest. The work-function curve for each patient was induced with methoxamine infusion to increase the afterload and measure both the end-diastolic pressure and cardiac index. Heart rate was maintained within a narrow range for each patient. Two of three patients responded well to the acute increase by the afterload stress. The slope was greater than 0.65 (Fig. 3). 


\section{Comment}

Our present approach to treat patients with d-TGA includes balloon atrial septostomy at the time of the initial cardiac catheterization. Patients with simple TGA will undergo the elective Mustard procedure at the age of 6-8 months. When the atrial communication is not adequate or increasing cyanosis is present, the Mustard procedure is carried out irrespective of its age or weight.

In patients with a large VSD and pulmonary hypertension or congestive heart failure, transatrial closure of VSD and the Mustard procedure have been both recommended before 6 months of age at our institute. However, the current operative mortality of the Mustard procedure in these patients has been as high as $30 \%$. Additionally, the incidence of late postoperative complications such as tricuspid regurgitation and dysrhythmias have been higher in this group. In such a case, the arterial repair described by Lecompte and associates (1981) may be justified as an optional operation for those with a large VSD and pulmonary hypertension.

Patients with VSD and severe left ventricular outflow tract obstruction who are less than 3 years old will be treated with a preliminary Blalock-Taussig shunt and subsequently a Rastelli operation. However, if the left ventricular outflow tract obstruction is correctable, the Mustard procedure with transatrial closure of VSD and transpulmonary resection of the obstruction is performed.

There has been no early postoperative death with simple TGA. Such improved results are due to refinements in the technique of extracorporeal perfusion, to the use of deep hypothermic circulatory arrest which allows more accurate intracardiac repair and to better intraoperative myocardial protection. Following the Mustard procedure, cardiac arrhythmias and baffle-related systemic and pulmonary venous obstruction have been the most common cause for the late postoperative death. In our hands, however, the incidence of cardiac dysrhythmias after the operation has decreased significantly since the application of direct high cannulation of the SVC and suture of the baffle away from the sino-atrial node. Obstruction of both superior and inferior venae cavae did not occur in our patients. It did not cause any other significant problems, either. Pulmonary venous obstruction (PVO) resulted from pericardial baffle constriction in one of our patients. The incidence of PVO has, however, decreased dramatically following the use of EPTFE intraarterial baffle.

Considerable concern still remains about the long term fate of the right ventricular function to carry out the load of systemic circulation. Several authors (Jarmakani and Cannent 1974 ; Graham et al. 1975; Borow et al. 1981) have reported abnormal systemic right ventricular function in patients with the Mustard procedure. These abnormalities include depressed RVEF in normal or increased RVEDV and normal or low right ventricular cardiac index. The clinical significance of these hemodynamic findings are, however, unknown, 
because the majority of patients are asymptomatic. And our findings show that the right ventricle in the physiologically repaired TGA patients can maintain normal cardiac output despite the afterload stress, and is hemodynamically well compensated at least in this early stage.

Recently, the Senning operation has become popular in many institutions. The theoretical merits of the Senning operation in which a potential for atrial growth is conceived have made this procedure of choice. The results of this operation are, however, not consistently good. The incidence of arrhythmias and pulmonary venous obstruction may be similar to that by the Mustard procedure since the extent of atrial disruption is similar to each other. Our laboratory data failed to show any growth of the atrial wall which was disrupted by the Senning operation. Furthermore, both procedures carry the same vexing problems with the right ventricle and tricuspid valve in the followup period.

Our results with the Mustard procedure for simple TGA is as good as those in recent reports from other institutions, in terms of the early and late mortality. We are still going to use the Mustard procedure and wait to see the long term hemodynamic studies in those who are subjected to alternative procedures.

\section{References}

1) Borow, K.M., Keane, J.F., Castaneda,. AR. \& Freed, M.D. (1981) Systenic ventricular function in patients with tetralogy of Fallot, ventricular septal defect and transposition of the great arteries repaired during infancy. Circulation, 64, 878-885.

2) Graham, T.P., Jarmakani, J.M., Atwood, G.F. \& Cannent, R.V. (1973) Right ventricular volume determinations in children: normal values and observation with volume or pressure overload. Circulation, 47, 144-153.

3) Graham, T.P., Atwood, G.F., Boncek, R.J., Boerth, R.C. \& Bender, H.W. (1975) Abnormalities of right ventricular function following Mustard operation for transposition of the great arteries. Circulation, 52, 678-684.

4) Horiuchi, T., Ishizawa, E., Ishidoya, T., Tanaka, S., Kuribayashi, R., Sato, S. \& Nitta, S. (1971) Surgical treatment of the complete transposition of the great arteries. Sinzo, 3, 863-873. (Japanese)

5) Ishizawa, E., Horiuchi, T., Ito, T., Yamaki, S., Sato, K., Sato, N., Tanaka, S., Suzuki, Y. \& Tadokoro, M. (1979) Recent experiences with the Mustard procedure for the complete transposition of the great arteries by means of "bypass hypothermia". Tohoku J. exp. Med., 127, 189-195.

6) Jarmakani, J.M. \& Cannent, R.V., Jr., (1974) Preoperative and postoperative right ventricular function in children with trnasposition of the great vessels. Circulation, 49, 50, suppl. 2, 39-45.

7) Lecompte, Y., Zannini, L., Hazan, E., Jadreau, M.M., Bex, J, P., Tu, T. V. \& Neveux, J.Y., (1981) Anatomic correction of transposition of the great arteries. New technique without use of a prosthetic conduit. J. thoracic cardiovas. Surg., 82, 629-631.

8) Mustard, W.T. (1964) Successful two-stage correction of the transposition of the great vessels. Surgery, 55, 469-472. 